\title{
Emotional Intelligence Relationship and Stress Work With the Performance of Nurses in Bolo Puskesmas of Bolo District Bima Regency Year 2018
}

\author{
Ayatullah \\ STIKES YAHYA BIMA \\ Email : ayatullahstikesyahya@gmail.com
}

\begin{abstract}
ABSTRAK : Dengan menunjukkan bahwa Pelayanan kesehatan yang dilakukan oleh tenaga kesehatan khususnya tenaga perawat belum menunjukan hasil optimal. Tujuan dalam penelitian ini yaitu untuk meningkatkan kinerja perawat dan untuk pengembangan ilmu pengetahuan serta untuk mengetahui hubungan motivasi dan kinerja perawat. Penelitian ini merupakan penelitian study kuantitatif dengan pendekatan cross sectional yang dilakukan pada perawat di Puskesmas Wotu Kecamatan Wotu Kabupaten Luwu Timur, mulai tanggal 09 agustus sampai 16 agustus 2018.Populasinya adalah perawat.Metode pengambilan sampel dengan Total Sampling. Jumlah sampel 64 responden. Hasil penelitian menunjukkan bahwa Pada analisa data dengan Chi-square diperoleh nilai $\mathrm{p}=0$.yang lebih besar dari nilai $\alpha(0,05)$ dengan demikian dapat disimpulkan bahwa tidak ada hubungan yang bermakna/signifikan antara, kecerdasan emosi dan kinerja perawat pada Puskesmas Bolo Kecamatan Bolo Kabupaten Bima begitu pun dengan hasil analisa data dengan Chi-square diperoleh nilai $\mathrm{p}=0$ yang lebih besar dari nilai $\alpha(0,05)$ dengan demikian dapat disimpulkan bahwa tidak ada hubungan yang bermakna/signifikan antara, Stress Kerja Dengan kinerja perawat pada Puskesmas Bolo Kecamatan Bolo Kabupaten Bima.Dari hasil ini disarankan kepada tenaga kesehatan agar kiranya dapat meningkatkan kecerdasan emosi dalam bentuk melakukan pelatihan-pelatihan dan terus menerus mengevaluasi kinerja hingga dapat memberikan kepuasan maksimal kepada pasien.
\end{abstract}

Kata kunci : Kecerdasan Emosi, Stress Kerja, Perawat dan Kinerja

\section{PENDAHULUAN}

Sumber daya manusia merupakan aset paling penting dalam suatu organisasi karena merupakan suber daya yang mengarahkan organisasi serta mepertahankan dan mengembangkan organisasi dalam berbagai tuntutan asyarakat dan zaman. Oleh karena itu, sumber daya manusia harus selalu diperhatikan, dijaga, dan dikembangkan.

Suatu badan organisasi atau badan usaha yang diharapkan dapat menujukkan eksistensinya dalam hal yang positif artinya mampu menunjukkan kinerja yang baik dimata pihak luar khususnya masyarakat, Peningkatan kinerja karyawan secara perorangan akan mendorong kinerja sumberdaya manusia secara keseluruhan, yang di refleksikan dalam kenaikan produktivitas. Kinerja karyawan yang tinggi akan membuat karyawan semakin loyal terhadap organisasi, seakin termotivasi untuk bekerja, bekerja dengan merasa senang dan yang lebih penting kepuasan kerja yang tinggi akan memperbesar kemungkinan tercapainya produktivitas yang tinggi pula.

Salah satu dari sekian banyak faktor yang mempengaruhi kinerja adalah faktor tenaga kerja atau manusia (individu itu sendiri). Oleh karena itu untuk dapat meningkatkan kinerja, maka salah satu hal yang perlu diperhatikan oleh seorang karyawan adalah kualitas emosional. Kualitas kualitas tersebut antara lain empati, mengungkapkan dan memahami perasaan, mengendalikan amarah, kemandirian, kemampuan menyesuaikan diri, kemampuan menyelesaikan masalah antar pribadi, ketekunan, kesetiakawanan, keramahan, serta sikap hormat [1].
Stres merupakan salah satu masalah yang mempengaruhi kerja di dalam organisasi menjadi gejala yang penting diamati sejak mulai timbulnya tuntutan untuk efisien di dalam pekerjaan. Setiap tenaga kerja bekerja sesuai dengan perannya dalam organisasi, artinya setiap tenaga kerja mempunyai kelompok tugasnya yang harus dilakukan sesuai dengan aturan aturan yang ada dan sesuai dengan yang diharapkan oleh atasannya. Namun demikian tenaga kerja tidak selalu berhasil untuk memainkan perannya tanpa menimbulkan masalah. Kurang baik berfungsinya peran, yang merupakan pembangkit stress yaitu meliputi konflik peran dan ketaksaan peran (role ambi guity) [2].

Stres kerja adalah sesuatu kondisi ketegangan yang menciptakan adanya ketidak seimbangan fisik dan psikis yang mempengaruhi emosi, proses berpikir, dan kondisi seorang karyawan [3].

Orang-orang yang mengalami stres menjadi nervous dan merasakan kekuatiran kronis sehingga mereka sering menjadi marah-marah, agresif, tidak dapat relaks, atau memperlihatkan sikap yang tidak kooperatif. Stres dapat bersifat positif maupun negatif. Stres yang bersifat positif disebut "eustres"yakni mendorong manusia untuk lebih dapat berprestasi, lebih tertantang untuk menyelesaikan masalah masalah yang dihadapinya, meningkatkan kinerja dan lain lain, Sebaliknya, stres yang berlebihan dan bersifat merugikan disebut "distress" menimbulkan berbagai macam gejala yang umumnya merugikan kinerja karyawan. Gejala gejala "distress" melibatkan baik kesehatan fisik maupun psikis.

Beberapa contoh gejala "distress" antara lain adalah gairah kerja menurun, sering membolos atau tidak masuk 
kerja, tekanan darah tinggi, gangguan pada alat pencernaan, dan lain sebagainya.

Dalam temuannya yang menunjukkan ada korelasi negatif antara stres kerja dengan kinerja pada karyawan, yang berarti semakin tinggi stres kerja maka akan semakin rendah kinerja karyawan [4].

Stres merupakan suatu keadaan dimana seseorang mengalami ketegangan karena adanya kondisi-kondisi yang mempengaruhi dirinya. Kondisi kondisi tersebut dapat ditimbulkan dari dalam diri individu maupun dari lingkungan di luar diri individu.

Keberhasilan seorang perawat tergantung pada pemahaman diri sendiri, kekuatan dan kelemahan serta pengaruh orang lain. Selain itu, mereka mempunyai ciri sebagai seorang perawat yang ramah, simpati, mudah bekerja sama, pandai menimbang perasaan, sikap sopan santun, dapat dipercaya, rendah diri, murah hati, berjiwa sportif, berpenampilan menarik, dan pandai bergaul dengan menunjukkan perilaku memberikan pertolongan dengan layanan terbaik pada pasien.

Untuk mewujudkan pelayanan yang optimal, maka tidak terlepas dari kinerja perawat dalam melaksanakan tugasnya, Kinerja perawat yang baik akan berimplikasi terhadap pelayanan yang baik pula, jika kinerja rendah atau buruk tersebut tetap dilakukan, maka perawat tidak akan naik jabatan dan akan di rotasi ke ruang lain. Selain itu, peningkatan melalui pendidikan ke jenjang yang lebih tinggi, mengikuti pelatihan keperawatan keterampilan teknis atau keterampilan dalam hubungan interpersonal. Program pelatihan adalah salah satu upaya untuk dapat meningkatkan kinerja pegawai dalam menghadapai berbagai macam perubahan baik internal maupun eksternal. Harapan dari model pelatihan ini akan mampu untuk meningkatkan kapasitas dan kapabilitas pegawai sehingga pada akhirnya tujuan industri pelayanan jasa akan dapat tercapai.

Dalam dunia kerja karyawan dihadapkan dengan berbagai tuntutan dan beban pekerjaan sehingga seorang karyawan perlu memiliki kecerdasan emosi dalam menghadapi pekerjaannya sehari hari, dalam kecerdasan emosi adalah kemampuan individu mengenali perasaan dalam diri sendiri dan orang lain serta memotivasi diri sendiri dan mengelola emosi emosi dalam diri sendiri serta dalam hubungan hubungan dengan orang lain [2].

Dalam hal peningkatan tenaga keperawatan, di kemukakan bahwa perkembangan pelayanan keperawatan saat ini telah melahirkan paradigma keperawatan yang menuntut adanya pelayanan keperawatan yang bermutu. Hal ini dapat dilihat dari adanya dua fenomena sistem pelayanan keperawatan yakni perubahan sifat pelayanan dari fakasional menjadi profesional dan terjadinya pergeseran fokus pelayanan asuhan keperawatan. Fokus asuhan keperawatan berubah dari peran kuratif dan promotif menjadi peran promotif, pereventif, kuratif dan rehabilitatif, untuk itu diperlukan tenaga perawat yang profesional yang dapat memberikan pelayanan keperawatan yang efektif, efisien dan bermutu.

\section{METODE PENELITIAN}

Penelitian ini adalah studi kuantitatif dengan pendekatan deskriptif Analitik dengan pendekatan cross sectional untuk melihat hubungan antara variabel independen dan variabel dependen secara bersamaan. Penelitian ini dilaksanakan di Puskesmas Bolo kecamatan Bolo Kabupaten Bima pada bulan Desember 2018. Sampel pada penelitian ini adalah total populasi teknik pengambilan sampel adalah 32 Perawat.

Analisa Data Univariat dilakukan terhadap semua variabel penelitian Analisis ini menghasilkan distribusi dan persentase dari masingmasing variable, Untuk mendeskripsikan semua variabel penelitian, baik variabel bebas maupun variabel terikat disajikan dalam bentuk tabel distribusi frekuensi dan narasi. Dalam penelitian ini data berdistribusi tidak normal maka menggunakan regresi logistik. Analisis Bivariat yaitu mendeskripsikan hubungan antara variabel bebas terhadap variabel terikat. Analisis pada penelitian ini dilakukan dengan dua cara yaitu analisis tabulasi silang dan chi square [5].

\section{HASIL DAN PEMBAHASAN}

\section{Analisa Univariat \\ Karakteristik Umum responden}

a. Distibusi Responden Berdasar kanjenis kelamin

Tabel 1. Distibusi Responden Berdasarkan jenis kelamin

\begin{tabular}{|c|c|c|}
\hline JenisKelamin & Jumlah & $\%$ \\
\hline Perempuan & $\mathbf{2 0}$ & $\mathbf{6 2 , 5}$ \\
\hline Laki-Laki & $\mathbf{1 2}$ & $\mathbf{3 7 , 5}$ \\
\hline Total & $\mathbf{3 2}$ & $\mathbf{1 0 0}$ \\
\hline Sumbe
\end{tabular}

Sumber : Data primer 2018

Tabel 1 tentang distribusi frekuensi berdasarkan jenis kelamin'dari 32 responden hamper sebagiannya yaitu $37,5 \%$ atau 12 responden berjenis kelamin lakilakidan $62,5 \%$ atau 20 berjenis kelamin prempuan

\section{b. Distribusi Responden Berdasarkan Usia}

Tabel 2. Distibusi Responden Berdasarkan usia

\begin{tabular}{|c|c|c|}
\hline Usia (Tahun) & Jumlah & $\%$ \\
\hline $20-30$ & 16 & 50 \\
\hline $31-50$ & 16 & 50 \\
\hline Total & 32 & 100 \\
\hline \multicolumn{2}{|c|}{ Sumber : data primer 2018}
\end{tabular}

Tabel 2 tentang data distribusi responden berdasarkan usia, dari 32 responden sebagian besarya itu 50\% atau 16 responden berusia 20-30 tahun,50\% atau 16 responden berusia 31-50 tahun dan 50\% .
c. Distribusi Responden Berdasar kan Jenjang pendidikan.


Tabel 3. Distibusi Responden Berdasarkan jenjang pendidikan

\begin{tabular}{|c|c|c|}
\hline Jenjang pendidikan & Jumlah & \% \\
\hline DIII & 17 & 53,1 \\
\hline SI & 15 & 46,9 \\
\hline Total & 32 & 100 \\
\hline
\end{tabular}

Sumber : data primer 2018

Tabel 3 tentang distribusi responden berdasarkan jenjang pendidikan, dari 32 responden sebagian besar yaitu $53,1 \%$ atau 17 dengan jenjang pendidikan DIII $46,9 \%$ atau 15 responden dengan jenjang pendidikan S1.

d. Distribusi Responden Berdasarkan lama kerja.

Tabel 4. Distibusi Responden Berdasarkan lama kerja

\begin{tabular}{|c|c|c|}
\hline Lama kerja ( tahun ) & Jumlah & \% \\
\hline $1-5$ & 14 & 43,8 \\
\hline $6-10$ & 10 & 31,2 \\
\hline $11-15$ & 8 & 25,0 \\
\hline Total & 32 & 100 \\
\hline
\end{tabular}

Sumber : data primer 2018

Tabel 4 tentang distribusi responden berdasarkan lama kerja dari 32 responden sebagian besaryaitu $43,8 \%$ atau 14 dengan lama kerja $1-5$ tahun, 31,2\% atau 10 responden dengan lama kerja 6-10 tahun dan 25,0\% dengan lama kerja 11-15.

e. Distribusi Responden Berdasarkan status.

Tabel 5. Distibusi Responden Berdasarkan status

\begin{tabular}{|c|c|c|}
\hline Status & Jumlah & \% \\
\hline Menikah & 20 & 62,5 \\
\hline Belum Menikah & 12 & 37,5 \\
\hline Total & 32 & 100 \\
\hline \multicolumn{2}{|r|}{ Sumber : data primer 2018 }
\end{tabular}

Tabel 5. tentang distribusi responden berdasarkan status dari 32 responden sebagian besar yaitu 62,5\% atau 20 dengan status menikah $37,5 \%$ atau12 responden dengan status belum menikah.

f. Distribusi frekuensi responden berdasarkan kecerdasan emosi

Tabel 6. Distribusi Frekuensi Responden Kecerdasan Emosional

\begin{tabular}{|c|c|c|}
\hline Kecerdasan emosional & Frekuensi & \% \\
\hline Tinggi & 19 & 59,4 \\
Rendah & 13 & 40,6 \\
\hline Total & $\mathbf{3 2}$ & $\mathbf{1 0 0}$ \\
\hline
\end{tabular}

Tabel 6 tentang distribusi frekuensi responden berdasarkan kecerdasan emosi, dari 32 responden dapat dilihat bahwa sebagian besar perawat di Puskesmas Bolo Kecamatan Bolo Kabupaten Bima memiliki Kecerdasan emosi tinggi (59,4\%) dibandingkan perawat yang memilki kecerdasan emosi rendah $(40,6 \%)$ atau kemampuan emosi didalam dirinya yang mendorong nya untuk bertindak berdasarkan standar keperawatan yang meliputi tanggung jawab, prestasi kerja, dan kerjasama.

Hal tersebut menunjukan bahwa upaya meningkatkan kecerdasan emosi perawat di Puskesmas Bolo Kecamatan Bolo Kabupaten Bolo diperlukan untuk mendukung dalam pelaksanaan pelayanan keperawatan.

\section{g. Distribusi Responden stress kerja}

Tabel 7. Distribusi Frekuensi Responden stress Kerja

\begin{tabular}{|c|c|c|}
\hline Stres kerja & Frekuensi & \% \\
\hline Tinggi & 6 & 18,8 \\
Rendah & 26 & 81,2 \\
\hline Total & 32 & 100 \\
\hline \multicolumn{2}{|c|}{ Sumber: Data Primer 2018 } \\
\hline
\end{tabular}

Tabel 7 tentang distriusi frekuensi responden berdasarkan stress kerja, dari 32 responden dapat dilihat bahwa sebagian besar perawat perawat di Puskesmas Bolo Kecamatan Bolo Kabupaten Bima memiliki stress Kerja tinggi $(18,8 \%)$ di bandingkan perawat yang memilki stress Kerja rendah $(81,2 \%)$

Hal tersebut menunjukan bahwa upaya meningkat kan stress kerja yang baik perawat di Puskesmas Bolo Kecamatan Bolo Kabupaten Bima diperlukan untuk mendukung dalam pelaksanaan pelayanan keperawatan

h. Distribusi Responden Menurut Kinerja Perawat

Tabel 8. Distribusi Frekuensi Responden Menurut Kinerja

\begin{tabular}{|c|c|c|}
\hline Kinerja & Frekuensi & \% \\
\hline Tinggi & 30 & 93,8 \\
Rendah & 2 & 6,2 \\
\hline Total & 32 & 100 \\
\hline \multicolumn{2}{|c|}{ Sumber: Data Primer 2018 } \\
\hline
\end{tabular}

Tabel 8 tentang distribusi responden berdasarkan kinerja , dari 32 responden dapat dilihat bahwa sebagian besar perawat perawat di Puskesmas Bolo Kecamatan Bolo Kabupaten Bima memiliki kinerja tinggi $(93,8 \%)$ dibandingkan perawat yang memiliki kinera rendah $(6,2 \%)$.

Hal tersebut menunjuk kan bahwa upaya meningkatkan kinerja perawat perawat di Puskesmas Bolo Kecamatan Bolo Kabupaten Bima diperlukan untuk mendukung dalam pelaksanaan pelayanan keperawatan

\section{Analisis Bivariat}

Untuk mengetahui hubungan variable bebas (kecerdasan emosi) terhadap variable terikat ( Kinerja Perawat ) maka dilakukan Tabulasi Silang dan Chi Square untuk membandingkan dan melihat hubungan 
/pengaruh setiap variable bebas terhdap variable tereikat seperti berikut :

a. Hubungan kecerdasan emosi terhadap kinerja perawat

Tabel 9. Hubungan kecerdasan emosi Terhadap Kinerja Perawat

\begin{tabular}{|c|c|c|c|c|c|c|c|}
\hline \multirow{3}{*}{$\begin{array}{c}\text { Kecerdasan } \\
\text { emosional }\end{array}$} & \multicolumn{4}{|c|}{ KinerjaPerawat } & \multirow{2}{*}{\multicolumn{2}{|c|}{ Total }} & \multirow{3}{*}{$P$} \\
\hline & \multicolumn{2}{|c|}{ Rendah } & \multicolumn{2}{|c|}{ Tinggi } & & & \\
\hline & $\mathrm{N}$ & $\%$ & $\mathrm{~N}$ & $\%$ & $\mathrm{~N}$ & $\%$ & \\
\hline Rendah & 1 & 7,7 & 12 & 92,3 & 13 & 100 & \\
\hline Tinggi & 1 & 5,3 & 18 & 94,7 & 19 & 100 & 0,078 \\
\hline Total & 2 & 6,2 & 30 & 93,8 & 32 & 100 & \\
\hline
\end{tabular}

Tabel 9 tentang distribusi responden ,ada 13 $(100 \%)$ orang Kecerdasan emosi rendah , kinerja perawat rendah ada $1(7,7 \%)$ orang, kinerja perawat tinggi ada $12(92,3 \%)$ orang , ada $19(100 \%)$ orang Kecerdasan Emosi Tinggi, kinerja perawat rendah 1 $(5,3 \%)$ orang, kinerja perawat tinggi $18(94,7 \%)$ Orang.

Dari uji statistik dengan menggunakan chisquare menunjukkan $\mathrm{p}$ value $0,078(<0,05)$ maka dapat disimpulkan tidak ada hubungan antara kecerdasan emosi dengan kinerja.

b. Analisis Pengaruh Lingkungan Kerja terhadap kinerja perawat

Tabel 10. Hubungan stress Kerja dengan Kinerja

\begin{tabular}{|c|c|c|c|c|c|c|c|}
\hline \multirow{3}{*}{ Stres kerja } & \multicolumn{4}{|c|}{ KinerjaPerawat } & \multirow{2}{*}{\multicolumn{2}{|c|}{ Total }} & \multirow{3}{*}{$P$} \\
\hline & \multicolumn{2}{|c|}{ Rendah } & \multicolumn{2}{|c|}{ Tinggi } & & & \\
\hline & $\mathrm{N}$ & $\%$ & $\mathrm{~N}$ & $\%$ & $\mathrm{~N}$ & $\%$ & \\
\hline Rendah & 2 & 7,7 & 24 & 92,3 & 26 & 100 & 492 \\
\hline Tinggi & 0 & 0 & 6 & 100 & 6 & 100 & \\
\hline Total & 2 & 6,2 & 30 & 93,8 & 32 & 100 & \\
\hline
\end{tabular}

Sumer: data primer agustus 2018

Tabel 10 tentang distribusi responden ada 26 $(100 \%)$ orang stress kerja rendah, ada $2(7,7 \%)$ orang kinerja perawat rendah , ada 24 (92,3\%) orang kinerja perawat tinggi, ada $0(0 \%)$ orang kinerja rendah dan ada $6(100 \%)$ orang kinerja tinggi .

Dari ujistatistik dengan menggunakan chi square menunjuk kan dengan $\mathrm{p}$ value $492(<0,05)$ maka dapat disimpulkan tidakada hubungan antara Stress Kerja dengan kinerja.

\section{Pembahasan}

1. Hubungan kecerdasan emosi terhadap kinerja perawat

Dari uji statistic dengan menggunakan chi square menunjukkan $\mathrm{p}$ value $0,078(<0,05)$ maka dapat disimpulkan tidakada hubungan antara kecerdasan emosi dengan kinerja.

Penelitian ini tidak sejalan dengan proses yang di lakukan oleh (DepKes, 2010) bahwa dengan kecerdasan emosi tinggi maka kinerja perawat akan semakin baik pada kecerdasan emosi rendah akan menghasil kan kinerja perawat kurang baik karena kecerdasan emosi merupakan kemauan atau keinginan didalam diri seseorang perawat yang mendorong nya untuk bertindak (Depkes, 2010)

Penelitian ini tidak sejalan dengan penelitian Reni dkk yang berjudul hubungan kecerdasan emosi dan stress kerja dengan kinerja dengan $\mathrm{p}=0,078$.

Peneliti menganalisis bahwa kinerja perawat bukan di tentukan oleh baik nya kecerdasan emosi maupun stress kerja, sebab ada hal lain yang mendorong akan peningkatan kinerja ini yang harus kita cari bersama sehingga efektif membangun kinerja yang bagus.

2. Hubungan stress Kerja dengan kinerja perawat

Dari uji statistic dengan menggunakan chi square menunjukkan dengan $\mathrm{p}$ value $492(<0,05)$ maka dapat disimpulkan tidak ada hubungan antara Stress Kerja dengan kinerja.

Penelitian ini tidak sejalan dengan penelitian Reni dkk yang berjudul hubungan kecerdasan emosi dan stress kerja dengan kinerja dengan $\mathrm{p}$ value 0,075 .

Peneliti menganalisis bahwa stress kerja bukan masalah besar dalam hal kinerja perawat, akan tetapi ada hal lain yang masih di perlukan untuk mengetahui lebih lanjut dengan kinerja ini.

\section{KESIMPULAN}

Kesimpulan dalam penelitian ini dapat disimpulkan bahwa: tidak ada hubungan antara kecerdasan Emosi dengan Kinerja perawat dengan nilai $\mathrm{P}=0,078>\alpha=0,05.2$. Tidak adahubungan antara (Stress Kerja) dengan (Kinerja perawat) dengan nilai $\mathrm{P}=0,942 \alpha=0,05$.

\section{DAFTAR PUSTAKA}

[1] Panyaman, J. Simajuntak. 2009. Manajemen Dan Evaluasi Kinerja. Jakarta : Lembaga Penerbit Fakultas Ekonomi Universitas Indonesia

[2] Goleman, D. 1999. Kecerdasan emosional untuk mencapai puncak prestasi. Jakarta: Widodo Gramedia Pustaka Utama

[3] Rivai, V. 2005. Performance Appraisal. Jakarta: Raja Grafindo Persada.

[4] Rosidah. 2003. Pengaruh Kompetensi SDM Terhadap Kinerja PT. Cheil Jedang Indonesia. Jombang

[5] Sugiyono. 2009. Dr. Statistik Untuk Penelitian. Bandung: CV Alfabeta. 